\title{
A Spatial Analysis of Unplanned and Mushrooming Dumpsites and Environmental Governance in Nairobi County
}

\author{
Florence Ogutu ${ }^{1 *}$, Dr. Dennis Kimata ${ }^{1}$ and Dr Raphael Kweyu ${ }^{2}$ \\ 1. Wangari Maathai Institute for Peace and Environmental Studies, University of Nairobi, P.O Box 30197 \\ - 00100 GPO Nairobi, Kenya \\ 2. Kenyatta University, P.O Box 43844 - 00100, Nairobi, Kenya \\ *Florence.akinyi@gmail.com
}

\begin{abstract}
Unplanned and mushrooming dumpsites in Nairobi County are growing at an alarming rate regardless of the socioeconomic status resulting in unclean, ugly outlook of the city. The creation of these unplanned dumpsites underscores the governance gaps that exist in the solid waste management (SWM) in Nairobi County. In a period of fourteen years, the unplanned dumpsites have an exponential growth that necessitates intervention in the mechanism of handling solid waste in Nairobi County. Environmental governance in solid waste management is becoming a key pillar in the proper waste management strategies and dominates the development discourse. Most Nairobi County residents are not conscious of proper and well-maintained waste management systems. The purpose of this study was to explicate the spatial analysis of the importance of environmental governance in Solid Waste Management in Nairobi County on why unplanned dumpsites are on the increase. The study area was the two hundred and seventy seven unplanned dumpsites distributed across Nairobi County. Sampling was done through spatial analysis, the data sources were mainly from Quick Bird images of 2003 and 2007, and WorldView2 images of 2013 and 2017. Other secondary data used were Nairobi County boundary shape-file, Kenya rivers shape-file, Kenya roads shape-file and Kenya settlements shape-file, they were all obtained from Survey of Kenya databases. This paper provides a platform for other researchers to conduct further investigation on the importance of environmental governance to promote sustainable Solid Waste Management in Nairobi County with a view of reducing the unplanned and mushrooming dumpsites.
\end{abstract}

Keywords: Solid Waste Management, Environmental governance, unplanned dumpsites, Nairobi County, Spatial analysis, Solid Waste Management

DOI: $10.7176 / \mathrm{JEES} / 9-10-17$

Publication date:October $31^{\text {st }} 2019$

\section{Introduction}

The continued mushrooming of dumpsites in Nairobi is as a result of domestic and industrial waste generation which continues to increase world-wide just as growth in consumption and the spur in urbanization. Notably in developed countries not withstanding Nairobi County, per capita waste generation has increased nearly three-fold over the last two decades, which translates to five to six times higher than that in developing countries (UNEP 2018). Developing countries for instance, have not effectively implemented measures that control mushrooming of dumpsites in urban cities (UNEP 2005, 2018). Solid Waste Management in Nairobi County is predominantly portrayed by ineffective collection methods, inadequate coverage of the collection system and improper disposal of municipal solid wastes and a growing culture of unplanned dumpsites. Funding for waste management is deemed inadequate, thus the costs are never fully recovered (UNEP 2005). Unplanned dumpsites in Nairobi city are growing in numbers and are due to poor garbage collection services offered by both the County government and other relevant service providers (Njoroge et al. 2014). There is a consensus that the various aspects of good governance are crucial in addressing Solid Waste Management challenges in cities globally, Nairobi City also included. Environmental governance incorporates rules, processes, and behavior by which interests are articulated, resources are managed, and power is exercised whose consequences are proactive in reducing unplanned dumpsites (Kazungu 2010). Thus, effective environmental governance frameworks of Solid Waste Management should include practical, implemented and well enforced laws and regulations that foster mechanisms of reducing unplanned dumpsites (Henry et al.2006) 
There should exist proper integration and collective implementation of both local and international conventions, policies and environmental administrative structures that ensure efficiency of service delivery is not compromised and capacity building on curtailing unplanned dumpsites enhanced (Guerrero et al.2013). Institutions that are mandated with ensuring that proper values that govern Solid Waste Management within a decision making process of their nations and individuals are essential (UNEP 2016). Human activities generate waste which can be harmful to the environment, animals, plants and the ecosystem indicating the impacts of unplanned dumpsites. However, only sound environmental governance can limit the damage done to the environment and reverse the mushrooming of unplanned dumpsites (Achere 2012).

Environmental governance in Solid Waste Management addresses the inadequate infrastructure, financing, lack of clear roles and responsibilities of these authorities and uncollected and uncontrolled disposal of waste in public areas which have made the task more difficult, hence public health and sanitation is threatened by increased unplanned dumpsites (Muniafu \& Otiato, 2010). Waste management systems in Africa currently are not well maintained at household level since thousands of tons of functional solid waste that are generated daily end up in open dumps and wetlands, contaminating surface and ground water and posing major health hazards to human beings and the environment as illustrated by the spatial analysis of the unplanned dumpsites in Nairobi County (Chuen et al.2011, Kimani 2007).

The increase in solid waste generation has not been accompanied by equivalent increase in the capacity of urban authorities to deal with this problem of mushrooming unplanned dumpsites. The proper management of waste has thus become one of the most pressing and challenging environmental problems in Nairobi County and in the entire county (JICA 2010, UNDP 2016). The inability of city authority to collect and dispose waste, has led to indiscriminate dumping which further contribute to poor sanitary conditions and incidences of environment-related health problems (Ikiara 2006; Oyake 2012; UN-Habitat 2018 ). This study sought to examine the importance of environmental governance in SWM in Nairobi County using a spatial analysis.

\section{Methodology}

The study adopted a descriptive research design which provided a framework to examine current conditions, trends and status of events. Descriptive research design is more investigative and focuses on a particular variable factor which is the unplanned and mushrooming dumpsites in Nairobi County. Data was collected in Nairobi County from existing high resolution Quick Bird images of 2003 and 2007, and WorldView-2 images of 2013 and 2017 , both supplied by Digital Globe. These images were selected on the basis of their spatial resolution and cloud cover percentage. Quick Bird has a spatial resolution of $60 \mathrm{~cm}$ while WorldView-2 has $50 \mathrm{~cm}$. The selected images had a cloud cover percentage of less than 10 per cent. Other secondary data used were Nairobi County boundary shapefile, Kenya rivers shape-file, Kenya roads shape-file and Kenya settlements shape-file both of them from Survey of Kenya databases. Field reconnaissance was carried out to record and collect data on the exact ground locations of some of the unplanned dumping sites in Nairobi County. This data was collected by visiting the dumping sites and recording their ground coordinates in a handheld GPS unit. Ground coordinates of two hundred and seventy seven unplanned dumping sites were collected and photographs of the sites taken. These images were composed of those acquired from 2003 to 2017. The 2003-2017 image acquisition periods was chosen because very high resolution satellite images that are suitable for dumping sites spatial analysis were only available from 2003.

Handheld GPS receiver was used to record the exact geographical locations of the different dumping sites that were subsequently used in helping to identify the corresponding dumping sites locations on the very highresolution satellite images. The digital camera was used to take photographs of all the dumping sites that were covered in the study. The shape.

-file of Nairobi City County was uploaded on the Digital Globe satellite image website for identification of the area of study.

\section{Results}

The results of the spatial analysis of the unplanned dumpsites in selected Nairobi neighborhoods were Lavington, Kibra and Embakasi. The results are presented in the following order: Spatial analysis of the study location; spatial analysis of the unplanned dumpsites in Nairobi County for the period of 2003- 2017 and unplanned dumping sites patterns in Lavington, Embakasi, Kibra and their environs. 
Study Location of Nairobi County: Spatial Analysis

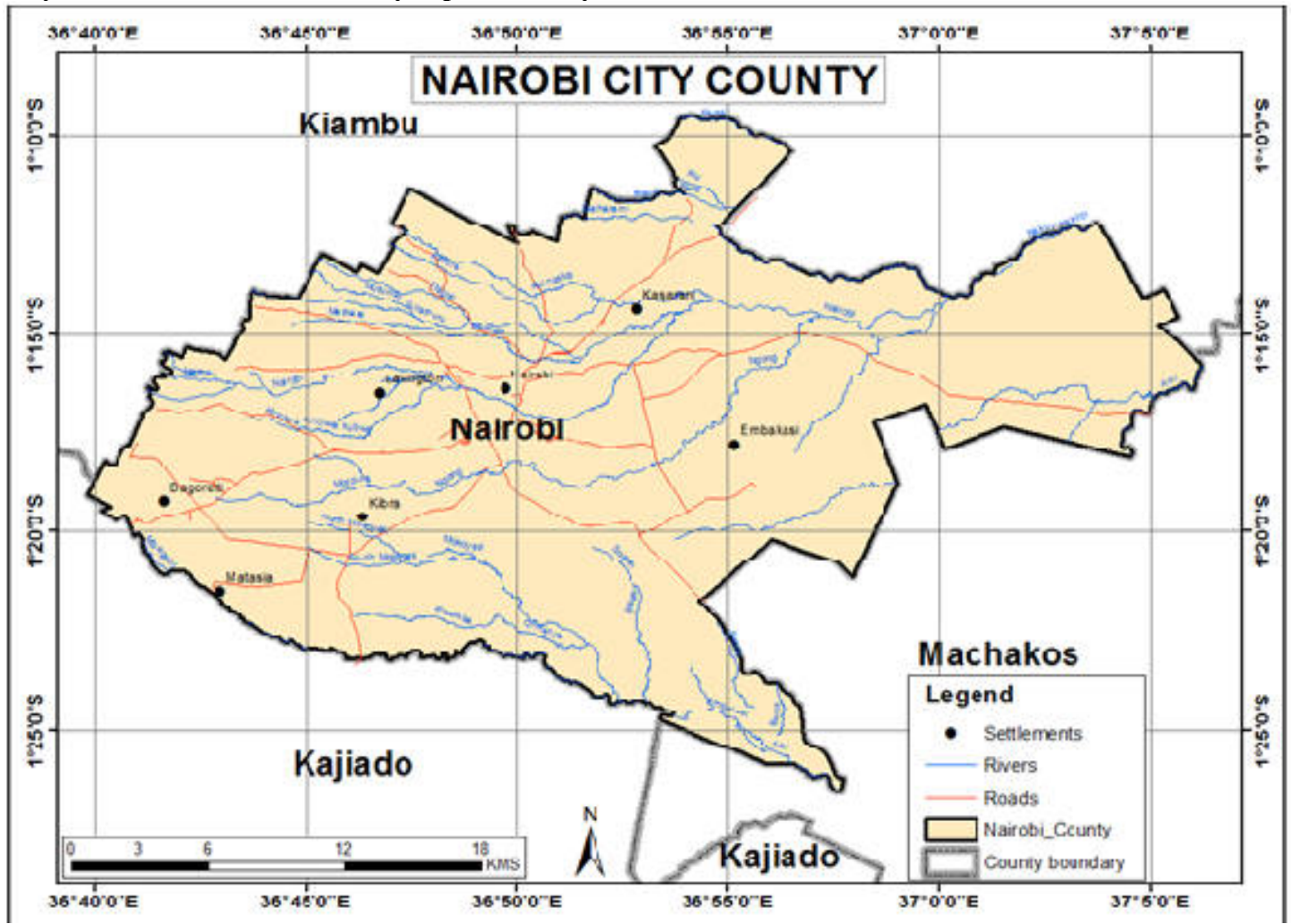

Figure 1: A map of Lavington, Embakasi and Kibra in Nairobi County

The Figure 1 shows the map of Nairobi County and the three focus areas of the study, namely Embakasi, Lavington and Kibra which are the common unplanned dumpsites area of the County and the spatial analysis for the said period illustrates that.

\subsection{A Spatial Analysis of the Unplanned and Mushrooming Dumpsites in Nairobi County for the Period of 2003- 2017}

High resolution satellite data were analyzed spatially to capture both the extent and the area covered by the unplanned dumping sites on different satellite image data sets. This was captured using object based satellite image interpretation and it involved on-screen digitization of areas covered by the dumping sites. The on-screen digitization depicted the difference in spatial coverage of the dumping sites in 2003, 2007, 2013 and 2017 indicating the mushrooming culture of unplanned dumpsites. The GPS points collected from the field were overlaid on the satellite images to identify the locations of unplanned dumping sites in Nairobi County. The spatial extents of the dumping sites on the different images were captured by digitizing polygons around the dumping sites. The spatial analysis results of the unplanned dumpsites in Nairobi County between the years 2003, 2007, 2013 and 2017 is as follows; 


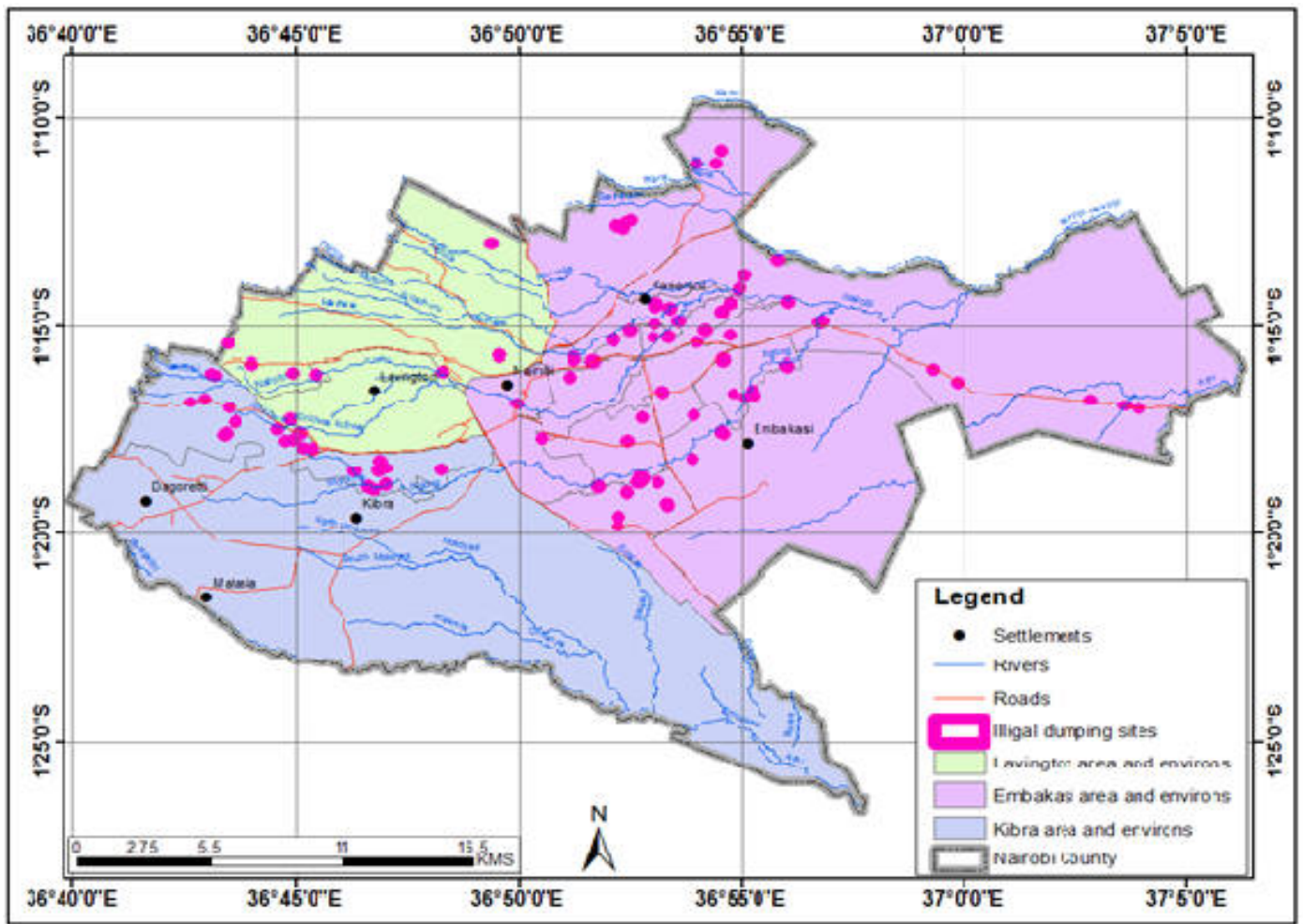

Figure 2: Distribution of unplanned dumping sites in Lavington, Embakasi and Kibra in 2003

The spatial analysis of the unplanned dumpsites in Nairobi County for year 2003 illustrates minimal unplanned dumpsites which resonates with the population in three Sub-counties of Nairobi County; Lavington, Embakasi and Kibra. 


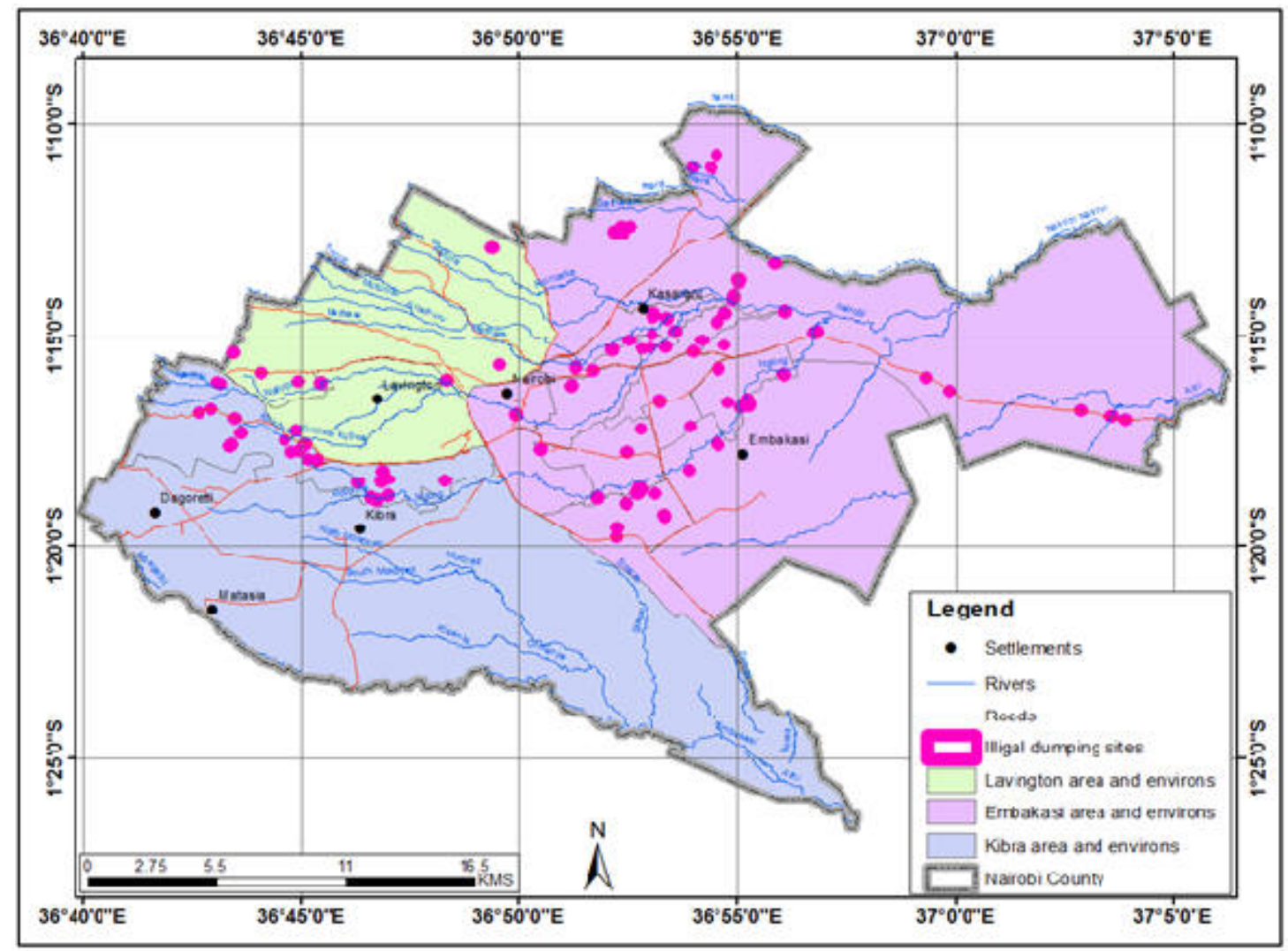

Figure 3: Unplanned Dumping Sites in Lavington, Embakasi and Kibra in 2007

The unplanned dumpsites in these sub-counties increased in a short span of four years which also was noted by the increase in population in these areas denoted by the spatial analysis. 


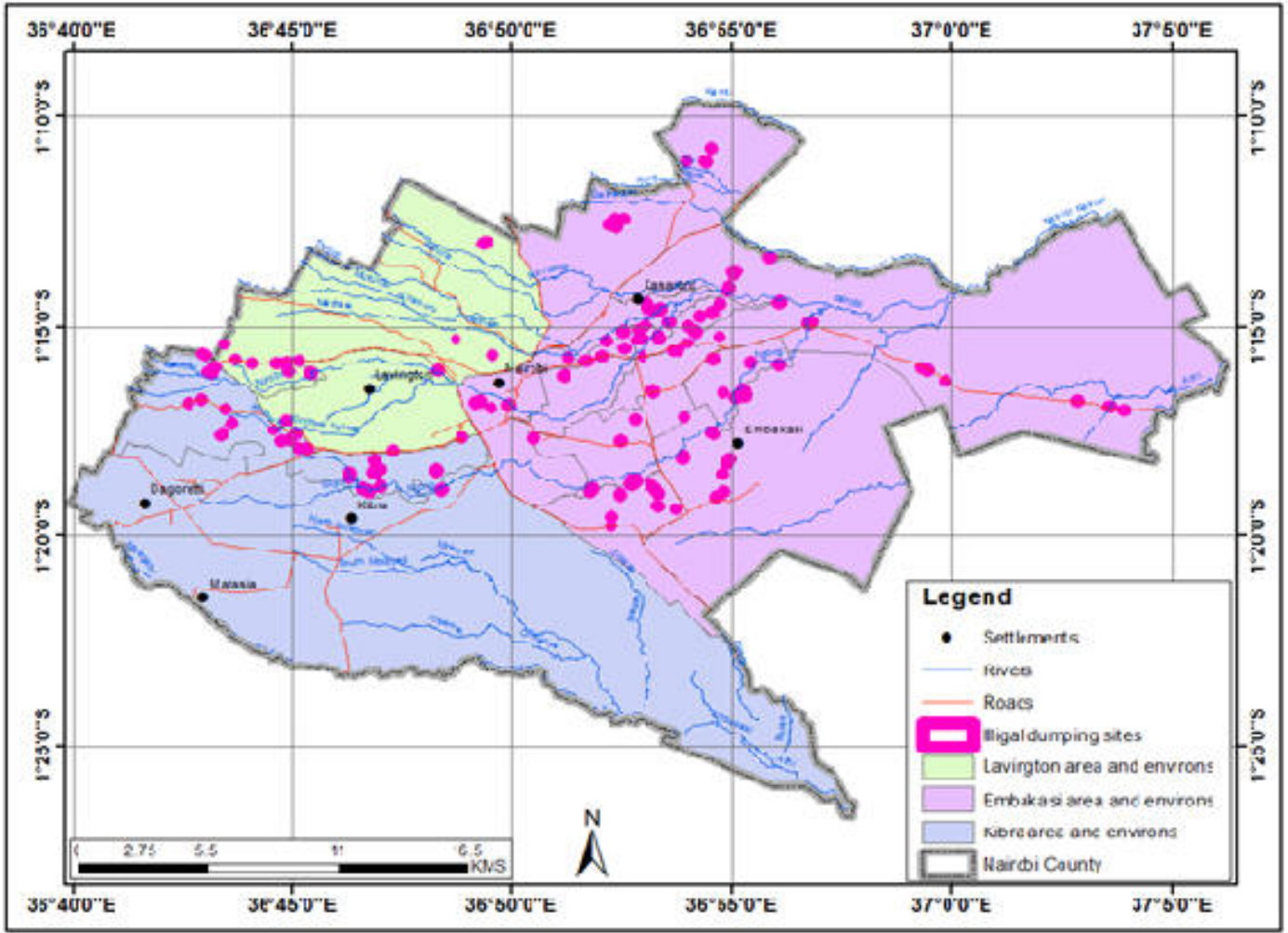

Figure 4: Unplanned dumpsites in Lavington, Embakasi and Kibra in 2013

This spatial analysis of the unplanned dumpsites in Nairobi County for 2013 shows that there was a double increase in the mushrooming of unplanned dumpsites in Lavington, Embakasi and Kibra. 


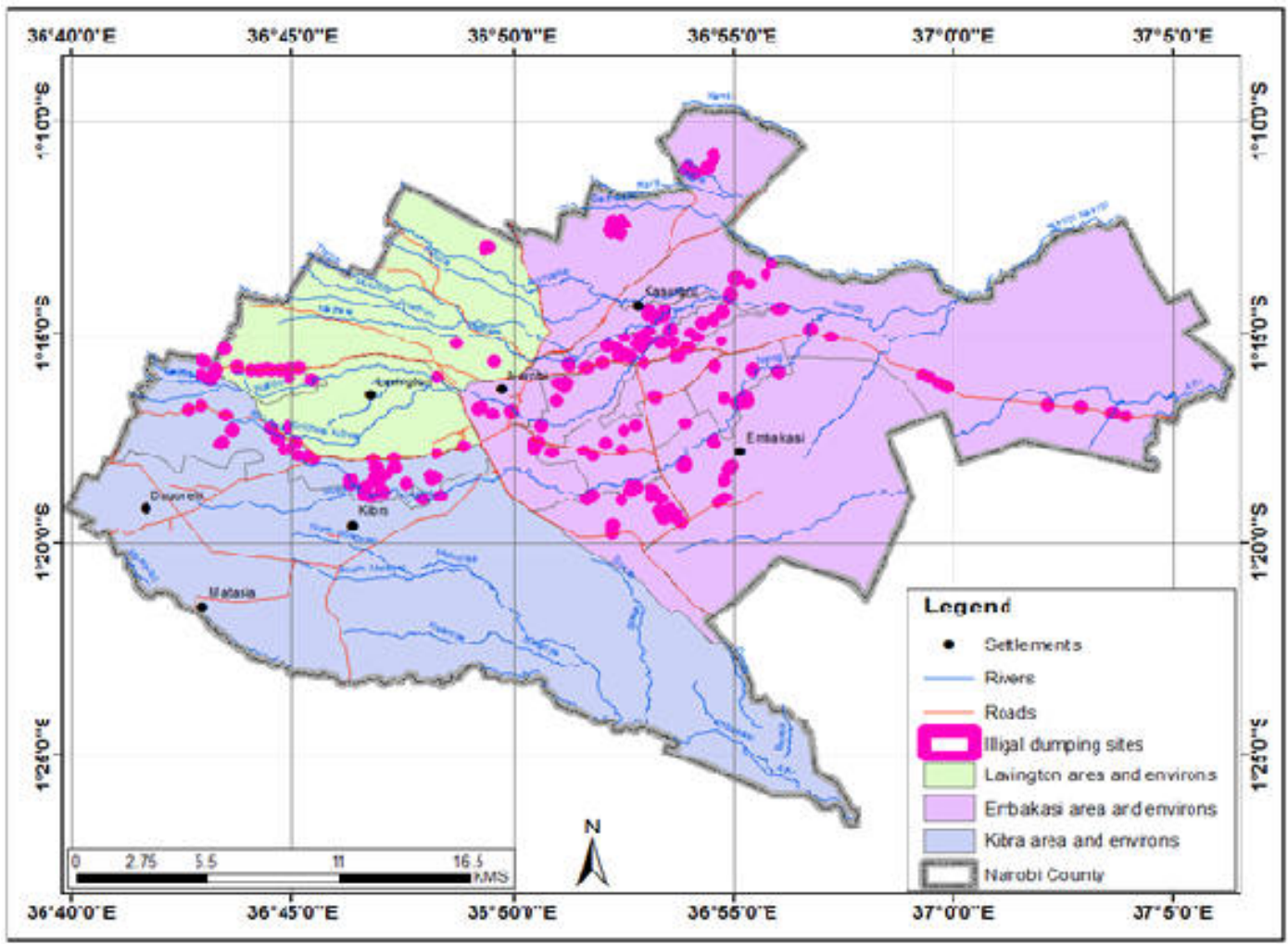

Figure 5: Unplanned dumping sites in Lavington, Embakasi and Kibra in 2017

By 2017 the unplanned dumpsites have huge growth rate especially in Kibra, Embakasi however Lavington was moderate.

\subsubsection{Mushrooming and unplanned dumping sites patterns in Lavington, Embakasi, Kibra and their Environs}

The unplanned dumping sites' spatial coverage in Nairobi between 2003 and 2017 was 7.35 ha, 7.96 ha, 11.03 ha and 16.94 ha in 2003, 2007, 2013 and 2017 respectively. From the study findings, the spatial area was determined by the extent of the unplanned dumpsites which was calculated in hectares. Embakasi had a larger spatial area of 6.55ha in 2003 to 15.04 ha in 2017, thus had more unplanned dumpsites unlike Lavington ( 0.25 ha, in 2003 to 0.53 ha in 2017). Kibra on the other hand had (0.55ha, in 2003 to 1.37 ha in 2017$)$ with the least number of dumpsites respectively.

\subsection{Discussion}

Nairobi County is one of the smallest Counties in Kenya and yet is the most populous County in terms of its population verifying the increased unplanned dumpsites. The rapid population growth has been due to a number of reasons such as employment opportunities, business opportunities and other factors that attract residents to the city whose solid waste generation will double (Hardoy et al. 2013; Gakungu et al. 2014; Njoroge et al. 2014). Just as the population of the city increases, so are the environmental challenges witnessed by mushrooming unplanned dumpsites in Nairobi County (Allison 2010; UNEP 2018; UN-Habitat 2016). Solid waste management in Nairobi has been a menace and the amount of solid waste generation has been on the increase to levels that have caused an uproar in its collection and disposal. Nairobi's status is largely characterized by low coverage of solid waste collection, pollution from uncontrolled dumping of waste, inefficient public services, unregulated and uncoordinated private sector and lack of key solid waste management infrastructure enhancing the growth of unplanned dumpsites (JICA 2010; UNDP 2016; NEMA 2014). The change in organic waste in these city locations 
and an increase in plastic and other non-biodegradable wastes can be attributed mainly to the residents changing lifestyles and the culture of dumping indiscriminately (UNEP 2016; UNDP 2016).

The analysis results from very high resolution satellite images indicate that the spatial coverage of unplanned dumping sites in the entire City of Nairobi was on the increase and this was attributed to the increase in population and no public awareness on waste disposal mechanisms. According to Census reports of 2009, the population of Nairobi County stood at 4 million residents with an increase of almost double expected by 2020 . This automatically would result to an increase in solid waste generation further illustrating the potential of growing unplanned dumpsites. Other major sources of solid waste were generated by the numerous economic activities and industrialization in Nairobi County with increased waste collection and disposal infrastructure (Muniafu \& Otiato 2010). In addition, Nairobi City has limited number of legal dumpsites and this meant that the existing sites were over time getting overwhelmed by the increase in waste generated. The Dandora dumpsite for instance, is the main dumpsite that serves the entire City and some of the wastes generated in other metropolitan towns like Kajiado, Kiambu and Machakos find their way to the same dumpsite (Henry, Yongsheng \& Jun 2006).

In a report by UNEP (2016), studies conducted by different urban planning experts recommended that the dumpsite be relocated to the nearby Ruai area to decongest the dumpsite but it has not been done. This was because the area had plenty of space to supplement the increasing waste generated by the City residents. Unplanned dumpsites are as a result of an overstretched legal dumpsite and management challenges which necessitate the importance of environmental governance (UNEP 2005; KNBS 2015; UNEP 2015).

Failure to effectively implement policies and regulations on solid waste management with institutions dealing with solid waste management lack synergy witnessed by lack of coordination and inefficiency resulting in increase in unplanned dumpsites (Troschinetz \& Mihelcic 2009; NEMA 2014). Additionally, Policies and regulations on solid waste management are inclined towards collection, transportation and disposal, with least emphasis on recycling and re-use which are critical to sustainable waste management. Public attitude towards waste management and lack of empowerment on environmental values and ethics is viewed as mere waste and not resources that can be harnessed to create wealth (Haregu et al. 2017; Oyake 2017).

\section{Conclusion}

The spatial analysis of the unplanned dumpsites in Nairobi County clearly brought out the importance of ensuring proper environmental governance structures that control emergence of unplanned dumpsites within Nairobi City. Good governance promotes equity, participation, pluralism, transparency, accountability and the rule of law done in a manner that is effective, efficient and enduring that can help overcome the challenges of solid waste management in urban cities like Nairobi County. Nairobi County is marred by lack of good governance in waste management, which is represented by the increased unplanned dumpsites, thus waste management institutionalization of good governance by bridging the gap between different stakeholders in solid waste management through inclusiveness and participation.

\section{Recommendation}

It is recommended that Nairobi County needs to adopt Solid Waste Management practices such as: ensuring they use sustainable waste dumping methods, proper recycling methods, sustainable collection and transportation of solid waste that suits the type of waste generated and creation of awareness and education among all stakeholders in their areas of jurisdiction

\section{References}

Achere, R (2012), Solid Waste Management. A World Perspective and the Cameroon case study. Master's Thesis. Universidad Fernando Pessoa, Porto Portugal.

Africa waste management outlook (2018). Summary for decision makers, United Nations Environmental Programme. CSIR, South Africa

Allison, K \& Von Blottnitz H (2010) Solid waste management in Nairobi, a situational analysis, technical document accompanying the integrated solid waste management plan. 
Chuen, KP, Lim YM \& Choong, CK. (2011). Household demand for solid waste disposal options in Malaysia, Germany University Library of Munich

European Commission (2004) "On Promoting Good Gernance." http://ec.europa.eu/europeaid/what/governance/documents/handbook pdf

Guerrero, LA, Maas, G \& Hogland W (2013). Solid waste management challenges for cities in developing countries. Waste Management, 33(1), 220-232. https://doi.org/10.1016/j.wasman.2012.09.008

Haregu. TN, Ziraba, AK \& Aboderin, I (2017) An assessment of the Evolution of Kenya's solid Waste Management Policies and their Implementation in Nairobi and Mombasa: analysis of Policies and practices. Environment and Urbanization 29:515-532.

Henry, RK, Yongsheng, Z \& Jun, D (2006) Municipal solid waste management challenges in developing countries - Kenyan case study. Waste Management, 26(1), 92-100. https://doi.org/10.1016/j.wasman.2005.03.007

High Level Panel of Experts on Food Security and Nutrition (HLPE). (2014) Sustainable Fisheries and Aquaculture for Food Security and Nutrition, Rome

Hardoy, JE, Mitlin, D \& Satterthwaite, D ( 2013 ) Environmental Problems in an urbanizing World:Finding solutions for cities in Africa, Asia and Latin America. Earthscan, London, UK and New York

Ikiara, C (2006) Opportunities and Challenges in Privatizing Urban Environmental Infrastructure: Lessons from the Dandora Dumpsite Nairobi. Paper presented at a Workshop on Public Expenditure and Service Delivery in Africa: Managing Public Expenditure to Improve Service Quality and Access.

Intermediate Technology Development Group ITDG-EA (2004) Regional Waste Management Report Experiences, challenges and opportunities of Waste Management in East African Urban Centers, Nairobi, Kenya.

ISWM Stakeholders Workshop Report (2009) Report on UNEP/City council of Nairobi 3rd ISWM Stakeholder Workshop to Identify Issues of Concern for the ISWM plan, December, 2009. Pan- Afric Hotel, Nairobi.

JICA (1998) The study on solid waste management in Nairobi City in the Republic of Kenya, final report. Japan International Cooperation Agency (JICA); in collaboration with CTI Engineering \& Environmental Technology Consultants. [Online]. Available from: http://lvzopac.jica.go.jp/external/library [Accessed 10 April 2009]

Kazungu, RK (2010) Improving Governance for sustainable solid waste management in Nairobi, $46^{\text {th }}$ ISCOCARP Congress, 1-8. https://doi.org/10.13140/Rg2.2.13490.61129

Kenya National Bureau of Statistics (2015). Kenya Facts and Figures, KNBS.

Kimani, N.G (2007) Environmental Pollution and Impacts on Public Health: Implications of the Dandora Municipal Dumping site in Nairobi, Kenya. United Nations Environment Programme (UNEP) - Urban Environment Unit. Available from: http://www.unep.org/urban environment/PDFs/DandoraWasteDumpReportSummary.pdf [accessed 3 May 2009]

Moghadam, MRA, Mokhtarani, N \& Mokhtarani, B (2009). Municipal Solid Waste Management in Rasht City, Iran.WM (New York) 29(1): 485-489. http://dx.doi.org (10.1016/j.wasman.2008

Muniafu, M \& Otiato, E (2010) Solid waste management in Nairobi, Kenya. A case for emerging economies. UR/:http://erepo.usiu.ac.ke/11732/316

National Environmental Management Authority (2014) The National Solid Waste Management Strategy, NEMA.

Ngau \& Kahiu (2009). ISWM Secondary Data Report on Solid Waste Inventory in Nairobi: Report of the National Technical Taskforce (NTT) on Preparation of An Integrated Solid Waste management Plan for Nairobi

Oyake, O (2012) Managing plastics waste in Urban Kenya, Niche Innovations in production and Recycling. Doctoral dissertation, Wageningen University, Netherlands. 
Oyake, O (2017) Awareness on Environmentally Sound Waste Management by Communities and Municipalities in Kenya, UNDP. Available at: file: users/veraweghmann/ Desktop/ Awareness \%environmentally\%Ssound\%soild\%20waste\%20management.Pdf

Troschinetz, AM \& Mihelcic, JR (2009) Sustainable Recycling of Municipal Solid waste in Developing Countries, WM, 29,915-923 https://doi.org/10.1016/j.wasman.2008.04.016.

UNDP IN KENYA (2016) Nationally Appropriate Mitigation Action on: A Circular Economy Solid Waste Management Approach for Urban Areas in Kenya, Ministry of Environment and Natural Resources, 2016.

UNEP, UN-HABITAT - Kenya (2007) City of Nairobi Environment Outlook, Nairobi, Kenya. United Nations Environment Programme (UNEP), United Nations Human Settlements Programme (UN Habitat), Kenya. [Online]. Available from: http://www.unep.org/DEWA/Africa/docs/en/NCEO_Report_FF_New_Text.pdf. [Accessed 10 May 2009]

UN-HABITAT (2016) UN-Habitat launches the World Cities Report 2016, Urbanization and Development: Emerging Futures - UN - Habitat. Retrieved from https://unhabitat.org/un-habita-launches-the world-citiesreport-2016

UN-HABITAT (2018) WASTE-WISE CITIES, a call for action to address the Municipal solid waste challenge: RETHINK.ACT, ENGAGE.

UNEP (2016) UNEP Frontiers 2016 Report: Emerging Issues of Environmental Concern. United Nations Environment Programme, Nairobi

United Nations Environment Programme (UNEP) (2018) Africa Waste Management Outlook. United Nations Environment Programme, Nairobi, Kenya. Available at: https://www.csir.co.za/documents/africa-wmo-reportpdf (accessed 10 July 2018).

United Nations Environment Programme and International Solid Waste Association (2015) Global Waste Management Outlook. Osaka: United Nations Environment Programme. Available at: https://www.researchgate.net/publication/283085861_Global_Waste_Management_Outlook_United_Nations Environment_Programme_UNEP_and_International_Solid_Waste_Association_ISWA accessed 13 July 2018).

UNEP (2005b), Solid Waste Management, Nairobi, Kenya United Nations Commission on Human Settlement (UNCHS) - Habitat (2001). Tools to support, participatory urban decision making. Nairobi, Kenya: UNCHS.

World Bank (1999). What a Waste: Solid Waste Management in Asia. Urban Development Sector Unit, East Asia and Pacific Region, World Bank, Washington, D.C 